\title{
An Empirical Analysis of Retirement and Marriage in Taiwan
}

\author{
Wen-Shai Hung \\ Department of Business Administration, Providence University, Taichung, Chinese Taipei \\ Email: wshung@pu.edu.tw
}

Received July 18, 2013; revised August 18, 2013; accepted August 28, 2013

Copyright (C) 2013 Wen-Shai Hung. This is an open access article distributed under the Creative Commons Attribution License, which permits unrestricted use, distribution, and reproduction in any medium, provided the original work is properly cited.

\begin{abstract}
This paper investigates the factors influencing changes in marriage following retirement in Taiwan. The data used are from the Survey of Health and Living Status of the Middle Aged Elderly in Taiwan. The Weibull models are used to estimate the hazard rates of divorce or separation after retirement. The factors of unobserved heterogeneity are also examined for the influences of divorce or separation after retirement. The main empirical results find that Mainlanders, Aboriginals, people with better educational attainments, people with poor health or poor relationship with family have higher hazard rates of divorce or separation than others. In contrast, people with more children and persons with higher income have lower hazard rates of divorce or separation than others. After considering unobserved heterogeneity, most estimated coefficients on the marriage hazard regressors are larger in magnitude than the corresponding coefficients in the reference model.
\end{abstract}

Keywords: Divorce; Separation; Weibull Model; Unobserved Heterogeneity

\section{Introduction}

This paper examines the factors influencing changes in marriages following retirement in Taiwan. According to the 2012 survey of Ministry of the Interior, the highest proportion rates of divorce were concentrated at the 10 14 years of marriage duration and the trends gradually declined during the recent 10 years. In contrast, the trends of divorce rates over 20 years were gradually increased during the same period. This implies that the changes in marriages and retirement behavior may have some special relationships and it is interested to do a deeper research.

Most previous studies on retirement behaviour in Taiwan were focused on the health status and health-care utilisation, living arrangements, and the economic well-being of the elderly. For example, Schoenbaum [1] used the Survey of Health and Living Status of the Middle Aged and Elderly in Taiwan data to test the effect of health on labour force transition among the elderly using four different measures ${ }^{1}$. He concluded that health is a

\footnotetext{
${ }^{1}$ The four types of health measures considered in his paper include: 1) a summary measure of limitations on activities of daily living (ADL), such as shopping and lifting; 2) a summary measure of health conditions, such as stroke and dizziness; 3 ) a summary measure of mood and depression using the Centre for Epidemiologic Studies Depression Scale (CES-D) that can measure how people have been feeling in the past week; and 4) health indices, such as crude birth rate, crude death rate, life expectancy at birth (years) constructed using an instrumental variables framework.
}

major determinant of labour force transition, regardless of how it is measured. Individuals in poor health are significantly more likely to retire than people in good health. In addition, Chen [2] used the 1989 Labour Force Survey by the Directorate-General of Budget, Accounting and Statistics in Taiwan to examine the effect of health status and health-care utilisation among the elderly. He noted that the proportion of old-old population was relatively low. Taiwan's elderly were more inclined to use health-care facilities than elderly in other developed economies.

Chang [3] used the data from the Survey of Health and Living Status of the Middle Aged and Elderly to examine the changes in living arrangements of the elderly in Taiwan between 1989 and 1995. He found that reduction in widowhood would be favorable for the elderly to live with a spouse only. Increases in educational attainments and economic independence will alter the elderly to live alone. In addition, the increasing age at marriage means that unmarried children are likely to be in the parental home for a longer period and thus minimize the strong trend toward independent living of the elderly.

Hermalin, Roan, and Chang [4] also used the data from the Survey of Health and Living Status of the Middle Aged and Elderly in 1996 to test the effect of demographic and socioeconomic trends on the economic well-being of the elderly. The data combined two panels, 
including the first panel 2669 respondents aged 67 and over and the second panel 2462 respondents aged 50 to 66 in 1996. In general, those who relied on children as their major source were reported lower incomes than those who relied on other major sources.

Furthermore, $\mathrm{Yu}$ and Chang [5] investigated the retirement behavior of public sector employees. They used the matched data sets from the Taiwan Manpower Utilization Survey from 1986 to 2002 . They analyzed the incentive effects of public-sector retirement regulations on the retirement timing of public sector employees. Further, they examined whether the sample attrition bias was serious in their framework. Their empirical results found that the regulations on retirement age and tenure had significant effects on the choice of retirement timing.

Hung [6] examined the determinants of retirement among the middle aged and elderly workers in Taiwan. The data used were from two waves of Survey of Health and Living Status of the Middle Aged and Elderly in Taiwan in 1996 and 1999. He considered the models without and with time-varying covariates on estimated retirement. He found that the model without time-varying covariates, older workers, female workers, Mainlander workers, and workers with eligible pension have higher hazard rates of retirement, and workers with better education have a lower hazard rate of retirement. Furthermore, for the model with time-varying covariates, workers with poor health have a higher hazard rate of retirement, in particular as workers being in poor health increase the hazard rates of retirement, other things being equal.

For the other developed countries, some early studies on the effects of retirement on marital satisfaction provide limited support for the view that retirement has a negative impact on marital wellbeing. For example, Moen, Kim and Hofmeister [7] used two waves of the Cornell Retirement and Well-Being Study in US in 1994-1995 and 1996-1997 to investigate whether couples' employment/retirement circumstances predict marital quality differently for men and for women. They found that initially, the retirement transition led to decreased marital satisfaction and increased marital conflict for men and women. The evidence complements the findings that homemaker wives' marital quality declines temporarily when their husbands retire. It is also consistent with Szinovacz's [8], who used the data from the National Survey of Families and Households in US to explore the impact of couples' employment/retirement patterns on indicators of marital quality, including conflicts, heated arguments, marital happiness. He claimed that marital problems during the retirement behavior are typically temporary and resolved within a few years after retirement.

Vaus and Wells [9] showed the paper from Shaw, Pat- terson, Semples and Grant [10], those who suggested that after retirement a balance in the relationship must be re-established based on a new set of routines and patterns of communication. The evidence indicates that as couples settle into retirement, a new balance is generally found and the role strain that couples experienced during the retirement transition is reduced.

Pienta [11] used data from the 1992 Health and Retirement Survey to compare the retirement behavior of husbands and wives. He found that the wives' retirement status is related to familial factors, economic resources, and spouses' personal characteristics supporting the new modes of retirement hypothesis. Husbands differ mainly in that familial and spousal attributes have more limited relationships with retirement behavior according to the usual modes of retirement hypothesis.

Smith and Moen [12] investigated factors related to retirees' and their spouses' individual and joint retirement satisfaction using decision-making theory and a life course perspective. The sample included retired respondents (ages 50 to 72 ) and spouses from the Cornell Retirement and Well-Being Study in US in 1994-1995 and 1996-1997. Although 77\% of retirees report retirement satisfaction, only $67 \%$ of their spouses are satisfied; even fewer couples (59\%) report joint satisfaction. Multivariate logistic regression analyses reveal that retirees' and spouses' individual and joint reports of retirement satisfaction are related to perceptions of spousal influence on the retirement decision, with effects varying by gender.

In sum, few papers analysed the issues of changes in marriages and retirement, particularly for exploring the related questions of the impacts of retirement on the domestic divisions of labour and on marital quality in this domain in Taiwan. This paper will use the duration analysis and micro data to fill this gap. First, it describes the factors influencing changes in marriages, including divorce, separation, or spouse's deceased following retirement in Taiwan. Second, it estimates the hazard rates of changes in marriages among the middle aged and elderly. Third, in addition to investigating the effect of unobserved heterogeneity of changes in marriages following retirement, it is well known that the duration analysis produces incorrect results if unobserved heterogeneity is ignored (Lancaster, [13]) $)^{2}$, and it is to find useful policies for retirement and marriage in Taiwan.

\section{Some Facts about Marital Status among the Middle Aged and Elderly in Taiwan}

Marital status always affects individual participation in work and retirement behaviour. For instance, once a man is married, he tends to have more opportunities to work,

${ }^{2}$ See Hosmer, Lemeshow and May [14] and Cleves, Gould, and Gutierrez [15] for a description of the frailty models. 
and perhaps an increased desire or need to work as he is likely to be the main earner for his family. In contrast, a married woman might do more housework and have a lower desire (less need or opportunity) to work. The survey of Taiwan and Fujian Areas shows that the proportion of the population who are married decreased with increasing age from $85.4 \%$ aged 50 to 54 to $39.3 \%$ aged 80 and over. In contrast, the proportion whose spouse was deceased increased with age from $5.7 \%$ aged 50 to 54 to $57.3 \%$ aged 80 and over in 2005 . The proportion of the population divorced or separated decreased with increasing age from $6.2 \%$ aged 50 to 54 to $1.6 \%$ aged 80 and over. In particular, for the Taiwanese traditional society, most people prefer to only marry once during their lives.

Therefore, this paper is interested to examine some hypothesis of changes in marriages following retirement in Taiwan: for example, does marriage improve or get worse following retirement? Do men and women report different marital outcomes following retirement? What happens to the division of labour between married men and women following retirement? May the hazard rates of separated or divorced after retirement be higher than before retirement?

\section{Research Methods}

\subsection{Data Source}

The data used are from the Survey of Health and Living Status of the Middle Aged and Elderly in Taiwan (hereafter, SHLS) to analyse retirement and marriage issues. The SHLS is an important and unique survey in Taiwan, the first large-scale panel data set collected and produced by the Taiwan Provincial Institute of Family Planning $(\text { TPIFP })^{3}$ and the Population Studies Centre in the University of Michigan (PSC, UM), and is available for the period from 1989 to 2007 . The project was initiated in 1989 with a survey of 4049 respondents aged 60 and above. These respondents were interviewed four times including a major follow-up interview in 1993. The SHLS survey was extended by a second panel of individuals aged 50 to 66 in 1996. The two 1996 questionnaires were very similar. The sample size for the first panel was 2669 individuals aged 67 and over, and the second panel had 2462 respondents aged 50 to 66 . In 1999 the first panel comprised 2310 respondents aged 70 and over, and the second panel had 2130 respondents aged 53 to 73 . In 2003 the first panel comprised 1743 respondents aged 74 and over, the second panel had 2035 respondents aged 57 to 73 , and the SHLS survey was again extended by a third panel of individuals aged 50 to 56. Until 2007, the first panel comprised 1268 respon-

\footnotetext{
${ }^{3}$ The Taiwan Provincial Institute of Family Planning was merged into
} the Bureau of Health Promotion, Department of Health in July 2001. dents aged 78 and over, the second panel had 1864 respondents aged 61 to 77 and the third panel had 1402 individuals aged 54 to 60 .

The main data used are from the second panel of SHLS and the sample aged 50 to 66 in 1996. In particular, the voluntary retirement can be taken at age 50 if individuals have worked for 25 years, or reached age 55 and worked for more than 15 years. The first panel in 1989 did not cover those aged 50 to 60 . For this reason the first panel has been discarded for this study, and instead this uses the second panel. The SHLS data represents a national random sample, the detailed information includes individuals, family, marital status, health, social support, employment, and economic status.

\subsection{Variables Specification}

\subsubsection{Dependent Variable}

According to the SHLS data, the sample consists of two groups, namely the currently married and the divorced or separated, except widowed. The former group remains married during the sample period and are known as "right-censored" of marriage duration. The latter group includes those divorced and separated during the sample period, and the date on which an individual started their last marriage and the exact age at which their marriage ended were observed. These are known as the "uncensored" of marriage duration. Therefore, marriage duration includes the period from when an individual first married to the end of the marriage for the "uncensored" duration spells, and they continue married for the "right-censored" duration spells. This variable can be categorized as a dependent variable. The uncensored variable is coded 1 for divorced or separated and 0 otherwise.

\subsubsection{Explanatory Variables}

The explanatory variables recorded in the SHLS data include 1) Demographic characteristics of respondent: age, gender, race, educational attainment, and health status. 2) Family structure and support: number of children, relationship with family, and residence status. 3) Economic and employment factors: household income and retirement.

First, the demographic characteristics of respondents are explored. The effect of ageing alone is important in explaining why people losing their married status. In particular, as people become older, they are more likely to die or lose their partner. From the SHLS data, age can be categorised into four groups: Age1 (aged 50 to 54), Age2 (aged 55 to 59), Age3 (aged 60 to 64), and Age4 (aged 65 to 66). In addition, females always have a longer life expectancy than males in Taiwan. That is, the numbers of females who lose their husbands are is 
greater than males who lose their wives. The Gender variable is coded 1 for female and 0 for male. Next, the Race variables have four groups, namely Race1 (Fujianese), Race2 (Hakka), Race3 (Mainlander), and Race4 (Aboriginal). For the education variable is divided into four levels of schooling, namely Edu1 (informal schooling), Edu2 (primary level: 1 to 6 years), Edu3 (high school level: 7 to 12 years) and Edu4 (college level: 13 to 17 years). For the health assessment, the SHLS survey identifies five levels including excellent, good, average, not so good, and poor. The Poorh variable is coded 1 for poor health, including "not so good" and "poor" health, and 0 for otherwise.

Second, the variables of family structure and support: the number of children can reflect marriage duration and living support. In particular, the traditional Chinese culture in Taiwan suggests that people with more children expect more family support in old age. There are 0 to 11 children for this variable. Next, the definition of relationship with family includes that people sharing, concerning, communicating, and caring with their family; particularly for the sickness, if the respondents could not believe or depend on their family and the variable can be defined as Poorla4, that is people with poor relationship with their family. The variables of residence status include Area1 (people living in urban), Area2 (people living in town), and Area3 (people living in rural). Basically, people with more children have lower hazard rates of divorce or separation. In contrast, respondents with poor relationship from their family have a higher hazard rate of losing their marriage.

Third, the economic and employment factors cover household income and retirement. If people have a better economic status or higher income, they might have a lower hazard rate of ceasing to be married. For the employment variables, the Retirement variable is coded 1 for respondent's retired and 0 for otherwise. Basically, if the retired people without earnings or pension benefits have higher hazard rates of losing their marriage.

However, the main limitation of this study is the survey data, the response rates on earnings and pension income were low, reflecting the reluctance of participants to divulge their true income. One more hidden danger of the SHLS data is the unknown accuracy of the responses given by the participants. No obvious means of verifying these responses exists. To solve the limitation of the SHLS is the lack of data on the interviewees' wages and their assets. This paper only uses the household income as an indicator of income to facilitate further analysis of changes in marriages following retirement. The descriptive and summary statistics are given in Table $\mathbf{1}$.

\subsection{Estimation Method: Duration Model}

Duration analysis has been developed in the field of bio-statistics to describe the timing of events. It has become a subject of increasing interest to applied economics, such as retirement issues in labour economics (Diamond and Hausman, [16]; Hung, [17]), and divorce topics in marriage economics (Hung and Ho, [18]). Therefore, this paper uses duration analysis and considers marriage duration in two groups, including right censoring (individuals who remain married during the sample period), and event or failure time (individuals do not remain married, including divorce or separation during the sample period). From these two sets of marriage duration, we can calculate the hazard rates of divorce or separation.

\subsubsection{Model without Unobserved Heterogeneity}

Weibull distributions are widely used as models for dura$t$ ion analysis. The hazard function of marriage duration without unobserved heterogeneity is specified as

$$
h\left(t \mid x_{i}\right)=\alpha t^{\alpha-1} \cdot \lambda=\alpha t^{\alpha-1} \cdot e^{\left(\beta_{0}+\beta_{i} x_{i}\right)} .
$$

Empirically, the parameters $\lambda$ and $\alpha$ in the Weibull distribution can be estimated by maximum likelihood. The parameter $\lambda$ depends on the explanatory variables $x_{i}$, thus providing us with a more flexible hazard function. For example, the hazard function is increasing if $\alpha>1$, decreasing if $\alpha<1$, and constant if $\alpha=1$. For observed duration data, $t_{1} ; t_{2}, \cdots, t_{n}$ the log-likelihood function can be formulated and maximized to include censored and uncensored observations. Combining the Weibull model into a general parametric likelihood yields:

$$
L(\beta)=\prod_{i=1}^{n}\left\{\left[f\left(t_{i} \mid x_{i}, \beta\right)\right]^{c_{i}} *\left[S\left(t_{i} \mid x_{i}, \beta\right)\right]^{1-c_{i}}\right\}
$$

where $\beta=(\lambda, \alpha)$, and $c_{i}=1$ represents uncensored observations, $c_{i}=0$ represents right-censored observations (Cleves, Gould, and Gutierrez, [15]). To obtain the maximum likelihood with respect to the parameters of interest, $\beta$, then maximise the log-likelihood function ${ }^{4}$ :

$$
\ln L(\beta)=\sum_{i=1}^{n}\left\{c_{i} \ln \left[f\left(t_{i} \mid x_{i}, \beta\right)\right]+\left(1-c_{i}\right) \ln \left[S\left(t_{i} \mid x_{i}, \beta\right)\right]\right\}
$$

The procedure to obtain the values of maximum likelihood estimation requires taking derivatives of $\ln L(\beta)$ with respect to $\beta$, the unknown parameters, setting these equations equal to zero, and solving for $\beta .^{5}$

\subsubsection{Model with Unobserved Heterogeneity}

After considering unobserved heterogeneity on estimated individual marriage behaviour, the hazard function can

\footnotetext{
${ }^{4}$ Since the $\log$ function is monotone, maxima of (2) and (3) occur at the same value of $\beta$; however, maximizing (3) is computationally simpler than maximizing (2).

${ }^{5}$ See Klein and Moeschberger [19], for a description of the numerical methods for implementing multivariate Newton-Raphson methods.
} 
Table 1. Descriptive statistics of variables.

\begin{tabular}{|c|c|c|c|}
\hline Variable & Description & Mean & Std. Dev. \\
\hline Duration & Duration of marriage between 1 and 50 years. & 32.032 & 7.755 \\
\hline Censor & $1=$ Uncensored, $0=$ Otherwise & 0.029 & 0.167 \\
\hline Age96 & $50-66$ years old in 1996. & 57.411 & 4.733 \\
\hline Age 1 & $1=$ aged 50 to $54,0=$ Otherwise & 0.323 & 0.468 \\
\hline Age2 & $1=$ aged 55 to $59,0=$ Otherwise & 0.326 & 0.469 \\
\hline Age3 & $1=$ aged 60 to $64,0=$ Otherwise & 0.256 & 0.436 \\
\hline Age4 & $1=$ aged 65 to $66,0=$ Otherwise & 0.093 & 0.291 \\
\hline Gender & $1=$ Female, $0=$ male & 0.437 & 0.496 \\
\hline Race1 & $1=$ Fujianese, $0=$ Otherwise & 0.728 & 0.444 \\
\hline Race2 & $1=$ Hakka, $0=$ Otherwise & 0.185 & 0.388 \\
\hline Race3 & $1=$ Mainlander, $0=$ Otherwise & 0.072 & 0.259 \\
\hline Race4 & $1=$ Aboriginal, $0=$ Otherwise & 0.013 & 0.115 \\
\hline Edu1 & $1=$ Informal education, $0=$ Otherwise. & 0.251 & 0.433 \\
\hline Edu2 & $1=1$ to 6 years of schooling, $0=$ Otherwise. & 0.463 & 0.498 \\
\hline Edu3 & $1=7$ to 12 years of schooling, $0=$ Otherwise. & 0.210 & 0.407 \\
\hline Edu4 & $1=13$ to 17 years of schooling, $0=$ Otherwise. & 0.075 & 0.263 \\
\hline Health1 & $1=$ Excellent Health, $0=$ Otherwise & 0.205 & 0.403 \\
\hline Health2 & $1=$ Good Health, $0=$ Otherwise & 0.237 & 0.425 \\
\hline Health3 & $1=$ Average Health, $0=$ Otherwise & 0.331 & 0.470 \\
\hline Health4 & $1=$ Poor Health, $0=$ Otherwise & 0.203 & 0.402 \\
\hline Health5 & $1=$ Very Poor Health, $0=$ Otherwise & 0.023 & 0.150 \\
\hline Poorh & $\begin{array}{c}1=\text { Poor and Very Poor Health, } \\
\quad 0=\text { Otherwise }\end{array}$ & 0.226 & 0.418 \\
\hline Children & $0-11$ children & 3.791 & 1.453 \\
\hline Poorla4 & $1=$ Poor relationship with family, $0=$ Otherwise & 0.052 & 0.222 \\
\hline Area1 & $1=$ People living in urban, $0=$ Otherwise & 0.381 & 0.485 \\
\hline Area2 & $1=$ People living in town, $0=$ Otherwise & 0.265 & 0.441 \\
\hline Area3 & $1=$ People living in rural, $0=$ Otherwise & 0.353 & 0.478 \\
\hline Income1 & $1=$ Less than NT $\$ 99,999,0=$ Otherwise. & 0.159 & 0.366 \\
\hline Income2 & $1=\mathrm{NT} \$ 100,000-299,999,0=$ Otherwise & 0.334 & 0.472 \\
\hline Income3 & $1=\mathrm{NT} \$ 300,000-599,999,0=$ Otherwise & 0.294 & 0.455 \\
\hline Income4 & $1=\mathrm{NT} \$ 600,000-999,999,0=$ Otherwise. & 0.127 & 0.333 \\
\hline Income5 & $1=$ Larger than NT $\$ 1,000,000,0=$ Otherwise & 0.084 & 0.277 \\
\hline Retirement & $1=$ retired, $0=$ Otherwise & 0.311 & 0.463 \\
\hline
\end{tabular}

Note: 1) The effective sample has 1556 observations, including 45 divorced or separated, and 1511 people who remain married. 2) The exchange rate was US $\$ 1$ $=$ NT\$27.457 in 1996.

be defined as

$$
h\left(t_{i} \mid x_{i}, u\right)=\alpha t^{\alpha-1} \lambda=\alpha t^{\alpha-1} \cdot e^{\left(\beta_{0}+\beta_{i} x_{i}+u\right)}
$$

where $u$ can represent unobserved heterogeneity, the differences between observations are introduced via a multiplicative scaling factor. This is a random variable taking on positive values, with the mean normalised to one and finite variance $\sigma^{2}$. A crucial assumption in the model is that $u$ is distributed independently of $x_{i}$ and $t$.
The other calculation procedures are same with the previous model without unobserved heterogeneity.

\section{Empirical Results}

\subsection{Model without Unobserved Heterogeneity}

Table 2 shows the estimated coefficients and hazard ratios of divorce or separation by Weibull model. For the benchmark individuals, all explanatory variables take a 
Table 2. Estimation by Weibull model.

\begin{tabular}{|c|c|c|c|c|}
\hline Variables & Coefficient & Standard Error & Hazard Ratio & Standard Error \\
\hline Age96 & -0.034 & 0.035 & 0.965 & 0.034 \\
\hline Gender & -0.293 & 0.359 & 0.745 & 0.268 \\
\hline Race2 & 0.012 & 0.497 & 1.012 & 0.503 \\
\hline Race3 & $1.365^{* * *}$ & 0.434 & $3.916^{* * *}$ & 1.702 \\
\hline Race4 & $1.895^{* * *}$ & 0.629 & $6.657^{* * *}$ & 4.190 \\
\hline Edu2 & $0.866^{*}$ & 0.503 & $2.377^{*}$ & 1.196 \\
\hline Edu3 & $1.531^{* * *}$ & 0.573 & $4.626^{* * *}$ & 2.654 \\
\hline Edu4 & 1.020 & 0.836 & 2.774 & 2.319 \\
\hline Poorh & $0.782^{* *}$ & 0.329 & $2.186^{* *}$ & 0.719 \\
\hline Children & $-0.506^{* * *}$ & 0.123 & $0.602^{* * *}$ & 0.074 \\
\hline Poorla4 & $1.225^{* * *}$ & 0.367 & $3.406^{* * *}$ & 1.250 \\
\hline Income2 & $-0.917^{* *}$ & 0.397 & $0.399^{* *}$ & 0.158 \\
\hline Income3 & $-1.339^{* * *}$ & 0.440 & $0.261^{* * *}$ & 0.115 \\
\hline Income4 & $-1.578^{* *}$ & 0.651 & $0.206^{* *}$ & 0.134 \\
\hline Income5 & $-2.703^{* *}$ & 1.107 & $0.066^{* *}$ & 0.074 \\
\hline Retirement & 0.196 & 0.347 & 1.217 & 0.422 \\
\hline Constant & $-4.317^{* *}$ & 2.155 & & \\
\hline$/ \ln \_\alpha$ & 0.135 & 0.142 & 0.135 & 0.142 \\
\hline$\alpha$ & 1.145 & 0.163 & 1.145 & 0.163 \\
\hline $1 / \alpha$ & 0.872 & 0.124 & 0.872 & 0.124 \\
\hline Log likelihood & \multicolumn{2}{|c|}{-205.652} & \multicolumn{2}{|c|}{-205.652} \\
\hline LR chi2 (16) & \multicolumn{2}{|c|}{83.55} & \multicolumn{2}{|c|}{83.55} \\
\hline
\end{tabular}

Notes: 1) The effective samples are 1,556 observations. 2 . Effects are significant at ${ }^{*} p \leq 0.10,{ }^{* *} p \leq 0.05,{ }^{* * *} p \leq 0.01$. 3) Goodness of fit: the result of Log-likelihood ratio test can reject the hypothesis that all coefficients except the intercept are 0 at the 0.01 level.

value of zero. That is, the benchmark individuals in all cases are relatively young Fujianese men with lower education attainments, no child, good health, with lower household income, and not retire. The hazard rate of divorce or separation estimates can be derived from the Weibull model of

$$
\begin{aligned}
h\left(t ; x_{i}\right) & =\alpha t^{\alpha-1} \lambda=\alpha t^{\alpha-1} \cdot e^{\left(\hat{\beta}_{0}+\hat{\beta}_{i} \cdot 0\right)} \\
& =1.145 * t^{0.145} * \exp (-4.317)
\end{aligned}
$$

In particular, $\alpha=1.145>1$ and $1 \leq t \leq 50$, which indicates the hazard rate has positive marriage duration dependence, $d h(t) / d t>0$. And $-\ln (1 / \alpha)=0.135$, the estimate suggests that the hazard rate of divorce or separation is increasing over time. As marriage duration gets longer, the hazard rate increases and people are more likely to divorce or separate.

First, for the age variables of respondents, Table 2 shows that the estimated coefficient of Age96 is negative and has lower hazard rates ceteris paribus, but statistically insignificant. The hazard ratio for Age96 is 0.965 .
This implies that older Taiwanese have 3.5\% lower hazard rates than otherwise and they are less likely to divorce or separate, ceteris paribus. The estimated coefficient of Gender is negative and has lower hazard rates ceteris paribus, but also insignificant. The hazard ratio for Gender is 0.745 . This implies that women have $25.5 \%$ lower hazard rates than otherwise and they are less likely to divorce or separate, ceteris paribus. In contrast, the estimated coefficients of Race 3 and Race 4 are positive and statistically significant and have higher hazard rates ceteris paribus. The hazard ratios for Race 3 are 3.916, and Race4 is 6.657. This implies that Mainlanders have $391.6 \%$ and Aboriginals have $665.7 \%$ higher hazard rates than Fujianese and they are more likely to divorce or separate, ceteris paribus. Furthermore, the estimated coefficients of Edu2 and Edu3 are positive and statistically significant and have higher hazard rates ceteris paribus. The hazard ratios for Edu2 are 2.377, and Edu3 is 4.626 . This implies that people with primary education have $237.7 \%$, junior and senior high school have $462.6 \%$ 
higher hazard rates than people with informal education and they are more likely to divorce or separate, ceteris paribus. For the variables of health status, Table 2 shows that the estimated coefficient of Poorh is positive and statistically significant and has higher hazard rates ceteris paribus. The hazard ratio for Poorh is 2.186 . This implies that people with poor health have $218.6 \%$ higher hazard rates than otherwise and they are more likely to divorce or separate, ceteris paribus.

Second, for the variables of family structure and social networks, Table 2 shows that the estimated coefficient of Children (number of children) is negative and statistically significant and has lower hazard rates. Especially, the hazard ratio for Children is 0.602 . This implies that respondents with children have $39.8 \%$ lower hazard rates than respondents without children and they are less likely to divorce or separate, ceteris paribus. Further, the estimated coefficient of Poorla4 (poor relationship with family) is positive and statistically significant and have higher hazard rates ceteris paribus. The hazard ratio of Poorla4 is 3.406. This implies that people with poor relationship from their family have $340.6 \%$ higher hazard rates than otherwise and they are more likely to divorce or separate, ceteris paribus.

Third, for the variables of economic status and employment, Table 2 shows that the estimated coefficients of Income2, Income3, Income4, and Income5 are negative and statistically significant and have lower hazard rates. The hazard ratios for Income2, Income3, Income4, and Income 5 are $0.399,0.261,0.206$, and 0.066 respectively. These show that people with higher household income have lower hazard rates than otherwise and they are less likely to divorce or separate. In contrast, the estimated coefficient of Retirement is positive and have higher hazard rates ceteris paribus, but statistically insignificant. The hazard ratio of Retirement is 1.217 . This implies that Retirement has $21.7 \%$ higher hazard rates than not retired and they are more likely to divorce or separate, ceteris paribus.

\subsection{Model with Unobserved Heterogeneity}

Frailty is a random component designed to account for variability due to unobserved individual-level factors of divorce or separation that are otherwise unaccounted for by the other predictors in the marriage duration model. Of particular note is the Poorla4 variable, which shows that $5.2 \%$ of people with poor relationship from family. When people are sick, they do not believe or depend on their careing.

Table 3 shows that the frailty model of all samples is assumed to follow a gamma distribution with mean 1 and variance equal to theta $(\theta)$. The estimate of theta is 0.269 . A variance of zero (theta $=0$ ) would indicate that the frailty component does not contribute to the model. A likelihood ratio test for the hypothesis theta $=0$ is shown directly below the parameter estimates and indicates a chi-square value of 3.31 with 1 degree of freedom yielding a highly significant $\mathrm{p}$-value of 0.034 . Notice how all the parameter estimates are altered with the inclusion of frailty. The estimate for the shape parameter is now 1.143 , different from the estimate 1.138 obtained from the model without frailty. The inclusion of frailty not only has an impact on the parameter estimates but also complicates their interpretation. Some estimated coefficients of the variables of Race4 (Aboriginals), Children (number of children), Income2, Income3, Income4, and Income 5 are slightly larger in magnitude than the corresponding coefficients in the reference model. The Weibull distribution shape parameter $\alpha$ is also slightly larger in the frailty model than in the reference model. Therefore, the effects of unobserved heterogeneity are important for examining the duration of marriage. Therefore, people need to consider the factors of unobserved heterogeneity and to improve the relationship with their families, they may be able for reducing the rates of divorce or separation in the modern society.

\section{Conclusions}

This paper investigates the factors influencing changes in marriages following retirement in Taiwan. The data used are from the 1996 Survey of Health and Living Status of the Middle Aged Elderly in Taiwan and the sample aged 50 to 66 .

First, for the demographic characteristics, the empirical results show those Mainlanders, Aboriginals, people with better educational attainment, and those in poor health have higher hazard rates and they are more likely to divorce or separate, ceteris paribus. Second, for the economic status and employment, people with higher household income have lower hazard rates and they are less likely to divorce or separate. In contrast, respondents retired have higher hazard rates and they are more likely to divorce or separate. Third, for the family structure and social networks, people with more children have lower hazard rates of divorce or separation. In contrast, the respondents with poor relationships from family have higher hazard rates and they are more likely to divorce or separate.

After considering the effect of unobserved heterogeneity from the factors of poor relationship (including difficultly sharing, concerning, communicating, and caring from their family), the estimated theta is larger than the model without unobserved heterogeneity. This implies that the influence of divorce or separation is more affected by the factors of unobserved heterogeneity. Particularly for the sickness, the respondents could not believe or depend on their family. To reduce the rate of divorce or separation, people may consider the factors of unobserved het- 
Table 3. Estimation by Weibull models without and with unobserved heterogeneity.

\begin{tabular}{|c|c|c|c|c|}
\hline \multirow{2}{*}{ Variables } & \multicolumn{2}{|c|}{ Without Unobserved Heterogeneity } & \multicolumn{2}{|c|}{ With Gamma-Heterogeneity } \\
\hline & Coefficient & Standard Error & Coefficient & Standard Error \\
\hline Age96 & -0.039 & 0.035 & -0.035 & 0.035 \\
\hline Gender & -0.222 & 0.352 & -0.274 & 0.356 \\
\hline Race2 & -0.027 & 0.495 & 0.001 & 0.496 \\
\hline Race3 & $1.404^{* * *}$ & 0.447 & $1.376^{* * *}$ & 0.435 \\
\hline Race4 & $1.842^{* * *}$ & 0.626 & $1.885^{* * *}$ & 0.627 \\
\hline Edu2 & $0.868^{*}$ & 0.495 & $0.867^{*}$ & 0.501 \\
\hline Edu3 & $1.672^{* * *}$ & 0.571 & $1.566^{* * *}$ & 0.573 \\
\hline Edu4 & 0.971 & 0.818 & 1.007 & 0.831 \\
\hline Children & $-0.533^{* * *}$ & 0.124 & $-0.512^{* * *}$ & 0.123 \\
\hline Poorhealth & $0.846^{* * *}$ & 0.324 & $0.799^{* *}$ & 0.327 \\
\hline Income2 & $-1.111^{* * *}$ & 0.389 & $-0.966^{* *}$ & 0.397 \\
\hline Income3 & $-1.538^{* * *}$ & 0.440 & $-1.387^{* * *}$ & 0.442 \\
\hline Income 4 & $-1.957^{* * *}$ & 0.641 & $-1.674^{* *}$ & 0.654 \\
\hline Income5 & $-2.879^{* * *}$ & 1.094 & $-2.745^{* *}$ & 1.103 \\
\hline Retirement & 0.180 & 0.343 & 0.192 & 0.345 \\
\hline Constant & $-3.689^{*}$ & 2.075 & -3.543 & 2.194 \\
\hline$/ \ln \_\alpha$ & 0.129 & 0.142 & 0.134 & 0.138 \\
\hline / ln_the & & & -1.311 & 1.196 \\
\hline$\alpha$ & $1.138^{*}$ & 0.162 & $1.143^{*}$ & 0.158 \\
\hline $1 / \alpha$ & $0.878^{*}$ & 0.125 & $0.874^{*}$ & 0.121 \\
\hline theta & & & $0.269^{*}$ & 0.322 \\
\hline Log likelihood & & & & \\
\hline LR chi2 (15) & & & & \\
\hline
\end{tabular}

Notes: 1) The effective samples are 1,556 observations. 2) Effects are significant at ${ }^{*} p \leq 0.10,{ }^{* *} p \leq 0.05,{ }^{* * *} p \leq 0.01$. 3) Goodness of fit: the result of Log-likelihood ratio test can reject the hypothesis that all coefficients except the intercept are 0 at the 0.01 level. In particular, Log-likelihood ratio test of theta $=0$ : chibar2 $(01)=3.31$, Prob $>=$ chibar2 $=0.034$.

erogeneity and how to improve their relationship with their family.

For the future work, this study will continually use the 1996-2007 panel data with the time-varying covariates analysis. People with poor health have higher hazard rates of divorce or separation, in particular as people being in poor health increase the hazard rates after retirement, other things being equal. Few changes in earnings or household's income may provide a stable marriage following retirement.

\section{Acknowledgements}

The authors would like to thank the Population and Health Research Centre, Bureau of Health Promotion for providing the Survey of Health and Living Status of the Middle Aged and Elderly in Taiwan data. Thanks also to the Korea National Research Foundation for providing partially funding of this research. The number is: NRF2011-220-B00027.

\section{REFERENCES}

[1] M. Schoenbaum, "The Health Status and Labour Force Behaviour of the Elderly in Taiwan," Research Report, University of Michigan, Ann Arbour, 1995, pp. 95-32.

[2] C. Chen, "Health Status and Health-Care Utilisation of the Elderly in Taiwan," In: C. Chen, A. I. Hermalin, S. $\mathrm{Hu}$ and J. P. Smith, Eds., Emerging Social Economic Welfare Programs for Aging in Taiwan in a World Content, The Institute of Economics, Academia Sinica, Taipei, 1999, pp. 279-303.

[3] M. Chang, "A Longitudinal Study on Living Arrangements of the Elderly in Taiwan," In: C. Chen, A. I. Her- 
malin, S. $\mathrm{Hu}$ and J. P. Smith, Eds., Emerging Social Economic Welfare Programs for Aging in Taiwan in a World Content, The Institute of Economics, Academia Sinica, Taipei, 1999, pp. 43-64.

[4] A. I. Hermalin, C. Roan and M. Chang, "The Economic Status of the Elderly in Taiwan," In: C. Chen, A. I. Hermalin, S. Hu and J. P. Smith, Eds., Emerging Social Economic Welfare Programs for Aging in Taiwan in a World Content, The Institute of Economics, Academia Sinica, Taipei, 1999, pp. 157-203.

[5] R. Yu and Y. Chang, "The Retirement Behaviour of Public Sector Employees in Taiwan," Working Paper, The Institute of Economics, Academia Sinica, Taipei, 2004 (in Chinese).

[6] W. Hung, "Duration Analysis for Retirement Decisions in Taiwan," Journal of Risk Management, Vol. 10, No.3, 2008, pp. 259-278.

[7] P. Moen, J. E. Kim and H. Hofmeister, "Couples' Work/ Retirement Transitions, Gender, and Marital Quality," Social Psychology Quarterly, Vol. 64, No. 1, 2001, pp. 55-71. http://dx.doi.org/10.2307/3090150

[8] M. Szinovacz, "Couples' Employment/Retirement Patterns and Perceptions of Marital Quality," Research on Aging, Vol. 18, No. 2, 1996, pp. 243-268. http://dx.doi.org/10.1177/0164027596182005

[9] D. Vaus and Y. Wells, "I Married Him for Better or for Worse But Not for Lunch: Retirement and Marriage," The 8th Australian Family Research Conference, Melbourne, 12-14 February 2003, pp. 1-22.

[10] W. S. Shaw, T. L. Patterson, S. Semples and I. Grant, "Health and Well-Being in Retirement: A Summary of Theories and Their Implications," In: M. H. and V. B. V. Hasselt, Eds., Handbook of Clinical Geropsychology, Plenum, New York, 1998, pp. 383-409.

[11] A. M. Pienta, "Partners in Marriage: An Analysis of Husbands' and Wives' Retirement Behavior," The Journal of
Applied Gerontology, Vol. 22, No. 3, 2003, pp. 340-358. http://dx.doi.org/10.1177/0733464803253587

[12] D. B. Smith and P. Moen, "Retirement Satisfaction for Retirees and Their Spouses: Do Gender and the Retirement Decision-Making Process Matter?" Journal of Family Issues, Vol. 25, No. 2, 2004, pp. 262-285. http://dx.doi.org/10.1177/0192513X03257366

[13] T. Lancaster, "The Econometric Analysis of Transition Data," Cambridge University, New York, 1990.

[14] D. W. Hosmer, S. Lemeshow and S. May, "Applied Survival Analysis: Regression Modelling of Time to Event Data," 2nd Edition, John Wiley \& Sons, Inc., New York, 2008. http://dx.doi.org/10.1002/9780470258019

[15] M. A. Cleves, W. W. Gould and R. G. Gutierrez, "An Introduction to Survival Analysis Using Stata," 3rd Edition, Stata Corporation, College Station, 2008.

[16] P. Diamond and G. A. Hausman, "Individual Retirement and Saving Behaviour," Journal of Public Economics, Vol. 23, No. 1-2, 1984, pp. 81-114. http://dx.doi.org/10.1016/0047-2727(84)90068-9

[17] W. Hung, "An Economic Analysis of Retirement Decisions in Taiwan," Ph.D. Dissertation, School of Economics, Finance and Business, University of Durham, Durham, 2009.

[18] W. Hung and S. Ho, "Duration Analysis of Marriage among the Middle Aged and Elderly in Taiwan," The Empirical Economics Letters, Vol. 8, No. 1, 2009, pp. 7987.

[19] J. P. Klein and M. L. Moeschberger, "Survival Analysis: Techniques for Censored and Truncated Data," 2nd Edition, Springer Science Business Medin, Inc., New York, 2005. 